\title{
Solutions for Stoning the Devil in Pilgrimage using Simulation
}

\author{
Mohammed Refai \\ Department of SE \\ Faculty of Information Technology \\ Zarqa University/Jordan
}

\begin{abstract}
Every year, more than two millions of Muslims went to the Holy city of Makah for pilgrimage "Hajj". There are a lot of activities that should be done during pilgrimage. One of the rituals performed by Muslim pilgrims during pilgrimage in alJamarat area in Mina, adjacent to Makah, is throwing stones at a pillar target. This activity is a symbol of stoning the devil "Throwing Jamarat" as done by Prophet Ibrahim. Throwing stones in mina during "aladha" eid is the most bottle neck ceremony. It caused a death of many Muslims last few years. This study suggests multi-solutions to solve the problem by using simulation program. Solutions include add more bridges; increase the radius of al-jamrat circles or using gates and semaphores. The suggested simulation presents any combination of the three solutions. The results of the study encourage adopting these solutions.
\end{abstract}

\section{Keywords}

Simulation, al-hajj, bridge, gates.

\section{INTRODUCTION}

Pilgrimage is one of the five main activities for all Muslims in the world. Pilgrimage is required from each Muslim only once in the life. Some Muslims do it more than once especially whom live inside Saudi Arabia. Number of Muslims whom willing to do Pilgrimage every year may exceeds five millions. The government of Saudi Arabia with the arrangement and coordination with other islamic countries apply a set of rules in order to restrict the number of pilgrims to be about two million per year. This restriction on the number of pilgrims per year is due to the limitations of the area of some ceremonies $[9,10]$.

One of the rituals performed by Muslims pilgrims during Pilgrimage near the Holy city of Makah is throwing stones at a pillar target. This activity is a symbol of stoning the devil (Throwing Jamarat) as done by Prophet Ibrahim. This activity is the most bottle neck ceremony among all other ceremonies overall the hajj activities. Each one of about two millions pilgrims should throw seven pebbles on a small area "circle with a radius of $7.5 \mathrm{~m}$ ". This job should be done within a short period of time " 5.5 hours is the shortest period over all years". Pilgrims do this activity on the 10th of Thi-Alhajeh (Arabic month); for the next two or three days, pilgrims throw twenty one pebbles on three sequenced regions, seven pebbles for each. When pilgrim reaches Mina, he should cast seven stones on the 10th of Thi-Alhajeh( the (Eid day) [11]. This act of throwing stones is called Rami(Arabic word means throw). During the stay at Mina on 11th, 12th and 13th days of thialhajeh the pilgrim cast seven stones on each of the regions in the following order: these are names in Arabic (Jamrah-tulOola, Jamrah-tul-Wusta, and Jamrah-tul-Aqaba). It is permitted not to cast stones on the third day [8].
The number of pilgrims increased significantly in the last few years. A walking bridge, 80 meters in width, was constructed over the three circles (Jamarat area) to ease conducting the activity. The pillar target was extended in height and penetrated the bridge to access throwing from the top level.

The Small and Medium Jamrah targets are encircled with a circular sink, at about waist height, to collect the stones.

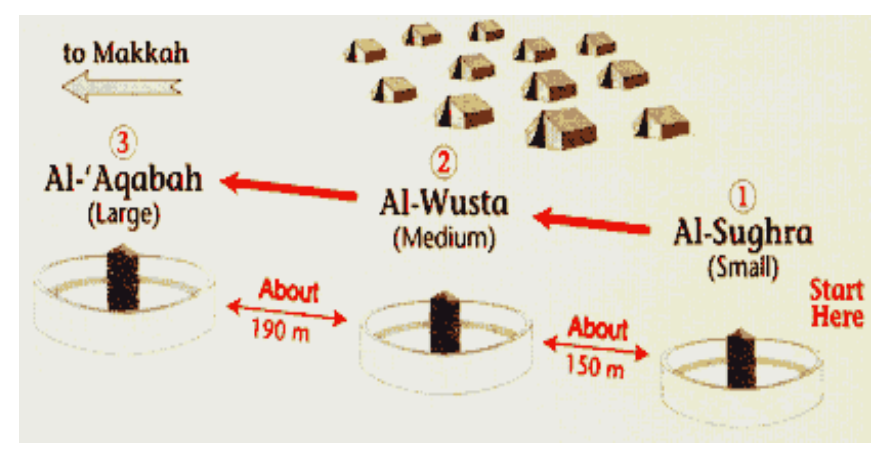

Figure-1. Three circles jamarat
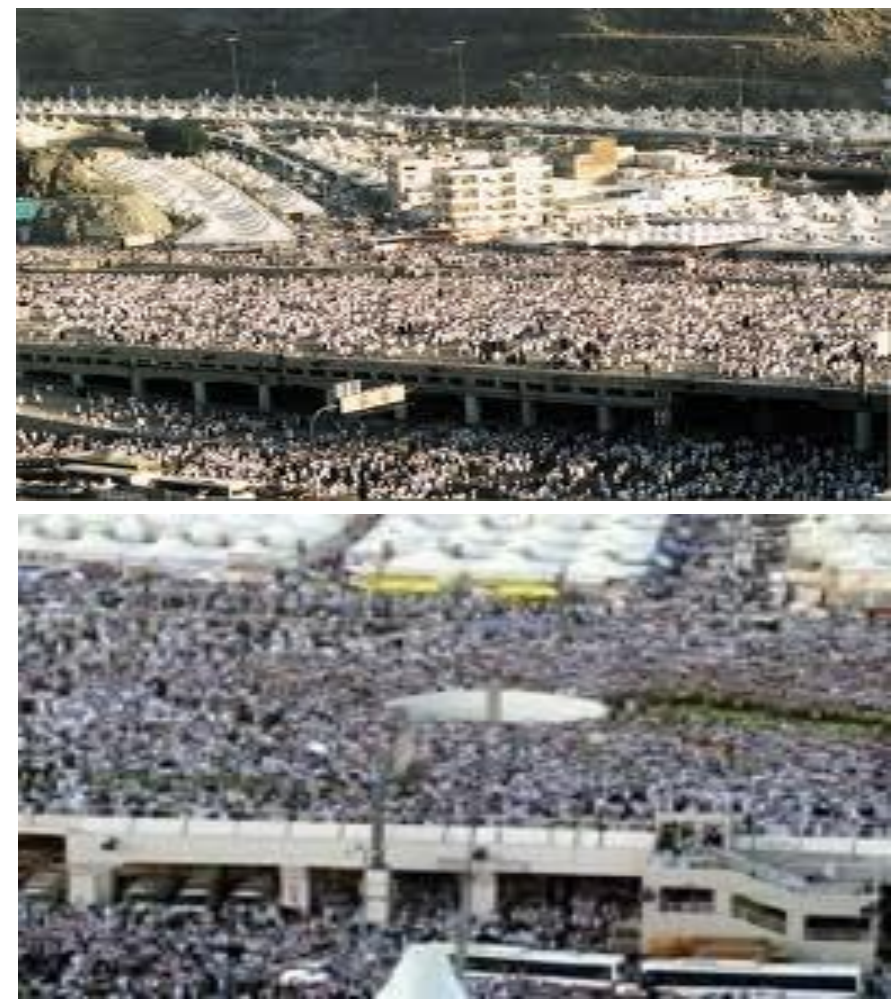

Figure 2: Congestion around aljamarat 
The Large Jamrah is surrounded with a semi-circular sink at the ground level and blocked at the other half while the top level is encircled with a circular barrier. The diameter of these sinks varies between 5 and 15 meters. The distributions of arrivals to the Jamarat area at each day $(10,11$, and 12$)$ is vary. This variation entails studying each day separately [2].

The stones are collected from the ground of a nearby location called Muzdalifa. At each Jamrah, the pilgrims approach the target, reach to a convenient distance, and start throwing at it. Reaching at a hitting distance is accomplished with difficulty. They are supposed to hit the target 7 times. In case they miss it, they try again. Therefore, they usually make sure that they carry more than seven stones for each

Jamrah. Some pilgrims prefer to throw at a close distance to make sure they hit the target. The density of people increases as one approaches the target. The distances between the three regions are $150 \mathrm{~m}$ and $190 \mathrm{~m}$ respectively [1].

\section{RELATED WORK}

Throwing stones in pilgrimage problem has been studied by some researchers. Muhammad H. Al-Haboubi in [12] presented an experiment of throwing stones at a target at various distances and introduced a new layout design for the Jamarat area. His new layout design is expected to smooth traffic and to reduce, or eliminate, safety hazards and ethical problems. Ghandoorah in [3] suggested to build many-level bridges and increasing the height of the target to be for all levels. This solution may be good and practical but the number of level should be determined correctly. In [4] authors suggested to reduce the high density periods of arrivals. This approach seems reasonable but requires a scientific study. In [5] Al-Gadhi also study the problem from the density of people around the target point view and he suggest to be uniform. This suggestion requires directing the attention of pilgrims to lower density spots. In [6] Selim and Al-Rabeh proposed a mathematical model to minimize a cost/penalty function by dividing the area into three parts: the waiting area, the throwing area, and the target area which is used for reaching towards the target. The result of the model determines the flow rate to the area which control the arriving pilgrims. It is harder to hit the target and may consume more time to complete seven hits. As a result, the area becomes more crowded and more dangerous. The averaged of throwing time in his study is 27 seconds and was found independent of either the distance from the basin of pilgrims.

\section{PROBLEM DEFINITION AND ANALYSIS}

The experiments showed that in most of the years, some pilgrims die because of the congestion on throwing the stones or (rami al-jamrat) especially on the first day "i.e. 10th Thi Alhajah" year $1424 \mathrm{H}, 314$ pilgrims were died. There are two reasons for this:

1. The limitation of the area and time (Constructions).

2. The unorganized of pilgrims (Organization).

The following are some statistics:

- About two millions pilgrims per year.

- $20 \%$ of pilgrims give the authority to other pilgrims to do "rami" instead of them.

- $52 \%$ of the pilgrims, whom do "rami", use the ground floor area.
- $48 \%$ of the pilgrims whom do "rami", use the bridge.

- $\quad$ Bridge length is about $600 \mathrm{~m}$

- Bridge width is about $40 \mathrm{~m}$

- Number of jamrat is three. See figure-1.

- The distances between the three jamrat are $150 \mathrm{~m}$ and $190 \mathrm{~m}$ respectively.

- $\quad$ Each jamrah is a circle of $7.5 \mathrm{~m}$ radius.

- The positions of all jamrat cannot be shifted according to religion fixed instructions.

- The shortest period of "rami" spans to 5.5 hours only.

- From the above information:

- $\quad$ Number of pilgrims whom use the bridge $=$ $2000000 * 0.8 * 0.48=768000$ pilgrims

- $\quad$ The required throughput $=$ $768000 /(5.5 * 60 * 60)=38.8$ pilgrims $/ \mathrm{sec}$

- Therefore, the average inter-arrival rate will be $1 / 38.8=0.026 \mathrm{sec}$ Simulation Model, design and Implementation

The simulation has the following prosperities:

- "Rami al-jamrat" should be done in sequence, "small one "Sokhra" then middle one "Wosta" then largest one "Aqaba".

- If Pilgrim arrives at jamrah and all slots around it are busy, then he/she joins one of the sixteen FIFO queue at that jamrah.

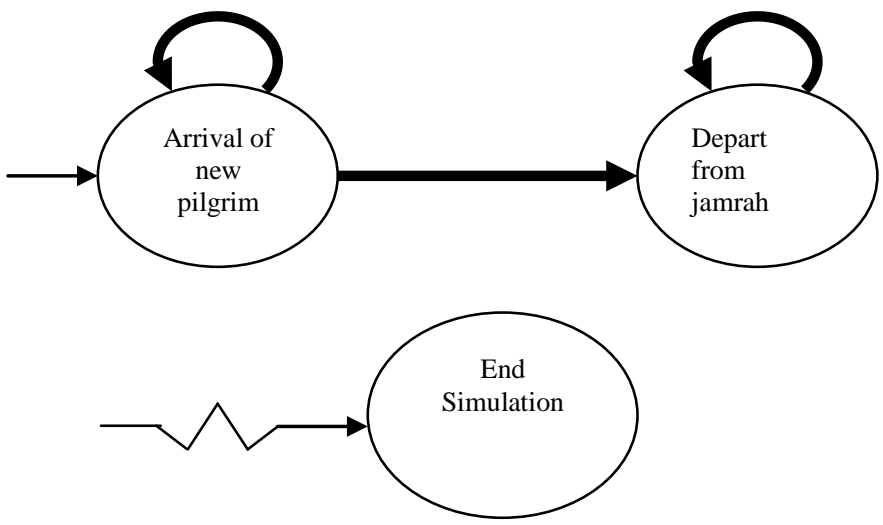

Figure-4 Event graph, "Rami Al-jamrat" model

Events:

Event description $\quad$ Event type

Arrival of new pilgrim 1

Departure of pilgrim 2

End of simulation $\quad 3$ 
- Simulation inputs include the following variables:

1. The mean time for "rami" on each jamrah and for each pilgrim.

2. The number of bridges up to 10 bridges.

3. The radius of the circle in each jamrah for all bridges.

4. The area for each Pilgrim is variable.

5. Number of rows for each jamrah: this variable means the maximum length that Pilgrim can throw the pebbles from.

6. Minimum rami interval for 7 pebbles.

7. External arrival $/ \mathrm{min}$.

8. Arrival to 1 st jamrah

\section{SIMULATION RESULTS}

When we applied the simulation with different inputs, the throughput column " which reflect the number of pilgrims they can do this ceremony with these inputs" shows deferent effects of these inputs. Two tables were studied as follow: Table 1 explains simulation results when the change is in radius of jamarat after 5 hours.

Table 1 results depends on radius

\begin{tabular}{|c|c|c|}
\hline Radius/m & $\begin{array}{c}\text { External } \\
\text { Arrival/min }\end{array}$ & throughput \\
\hline 5 & 10000 & 1034590 \\
\hline 8 & 10000 & 1070034 \\
\hline 10 & 10000 & 1086178 \\
\hline 11 & 10000 & 1063262 \\
\hline 12 & 10000 & 1034562 \\
\hline 13 & 10000 & 1020041 \\
\hline
\end{tabular}

From table 1 the simulation proof that the number of pilgrims increases as the jamarat radius increased up to 10 meters and then the number start decrease with long radius. This mean that the Increasing in the radius of circles increase the throughput up to determined limit then it was go to negative effect. Figure 5 show the relationship between radius and throughput.

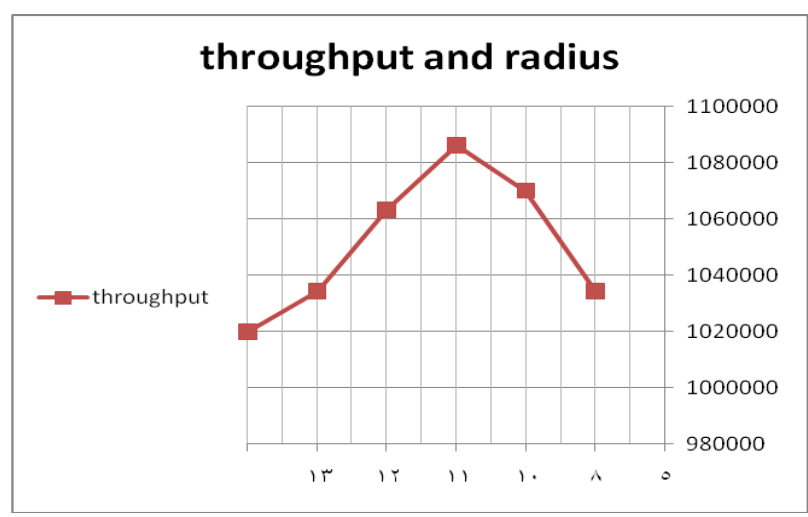

Fig 5 relation between radius and throughput
Table 2 explains simulation results, when the changes were in the number of bridges with fixed radius of jamarat $=10$ after 5 hours

In table 2 simulation results shows that the number of pilgrims is increased when we add more bridges.

Table 2 results depends the number of bridges

\begin{tabular}{|l|c|l|l|}
\hline Bridges & Radius/m & $\begin{array}{l}\text { External } \\
\text { Arrival/ } \\
\text { min }\end{array}$ & throughput \\
\hline 1 & 10 & 10000 & 686258 \\
\hline 2 & 10 & 10000 & 875480 \\
\hline 3 & 10 & 10000 & 1086178 \\
\hline
\end{tabular}

\section{CONCLUSION}

It is clear from table-1 above that if jamrah radius is expanded to $10 \mathrm{~m}$ instead of $7.5 \mathrm{~m}$ congestion problem can be solved and from table 2 the use of more bridges can solve the problem completely more solutions can be done by applied electronic gates to control the distribution of pilgrims among bridges up to congestion state.

About future work in pilgrimage studies, we see the new technology can assist in solving many problems. For example electronic identification for pilgrims and mobile application that can be used in travelling and accommodations.

\section{ACKNOWLEDGMENT}

My thanks to Zarqa University /Jordan who supported this research.

\section{REFERENCES}

[1] Al-Zahrani, A. 1989. Requirements of elderly people and handicapped during Hajj. Proceedings of Transportation in Hajj Symposium, Makkah, 125-143 (in Arabic)

[2] Al-Hajj Research Center Summary, 1990(1410 H.). Study of Jamarat, Makkah(in Arabic).

[3] Ghandoorah, A. 1988. Suggested Solutions for Tawaf, Saee, throwing stones at Jamarat, accommodation and transportation in Makkah, 105-121 (in Arabic).

[4] Barhamin, S. and Muhrez, W. 1989. An analytical study for pedestrian walkways in Mena valley. Proceedings of Transportation in Hajj Symposium, Makkah, 97-117 (in Arabic)

[5] Al-Gadhi, S. 1990. Charactrization of crowd behavior and movement, unpublished dissertation, The University of Texas, Austin.

[6] Selim, S. and Al-Rabeh, A. 1991. On the modeling of pedestrian flow on the Jamarat bridge, Transportation Science, Vol. 25, No. 4, 257-263

[7] Al-Haboubi, M. 1992. Anthropometry for a mix of different populations, Applied Ergonomics, Vol. 23, No. 3, 191-196.

[8] Habib M. Zein Alabideen, The Development of Jamarat Bridge and Surrounding Area, Deputy Minister, Ministry of Municipal and Rural Affairs. 
[9] Averill M. Law, W. David Kelton: Simulation Modeling and Analysis, 3rd edition,2000

[10] C. Dennis Pegden, Robert E. Shannon, Randall P. Sadowski: Introduction to Simulation Using SIMAN, 2nd edition.

[11] Deitel \& Deitel: C++ How to Program, 5th edition.

[12] Muhammad H. Al-Haboubi, A new Layout Design for the Jamarat Area (Stoning the Devil), Systems Engineering Department, King Fahad University for Petroleum and Minerals, Dhahran, Saudi Arabia, 2007.

\section{AUTHOR'S PROFILE}

Mohammed Al Refai received his PHD in Computer Science (CS) from Amman Arab University for Graduated studies, Jordan, 2/2007, M.S degree in CS from Alalbayet University, Jordan, $3 / 2002$. He received his undergraduate studies in CS from mutah university, Jordan, 6/1992. He is currently the chairman of Software Engineering Department in IT faculty in Zarqa University in nadroJ. His main research interests include many aspects in parallel and distributed systems, Simulation and Data Mining. 